ISSN: 0213-2087 eISSN: 2444-7080

DOI: http://dx.doi.org/10.14201/shhc2018361324

\title{
HERMENÉUTICA ANALÓGICA, JUSTICIA Y DERECHOS HUMANOS
}

\section{Analogenic Hermeneutics, Justice and Human Rights}

\author{
Mauricio BEUCHOT \\ Universidad Nacional Autónoma de México UNAM \\ mbeuchot50@gmail.com
}

Recepción: 27/04/2018 Revisión: 14/05/2018 Aceptación: 26/06/2018

RESUMEN: En este artículo se trata de exponer la aportación de los filósofos de la Escuela de Salamanca, que utilizaron los derechos naturales como antecedentes de los derechos humanos de hoy. Eran derechos subjetivos, que provenían de la línea nominalista de Paría, donde estudiaron Vitoria y Soto. Por eso historiadores del derecho, como Blandine Barrett-Kriegel los han visto como antecedentes de los derechos humanos en la línea de las teorías de la justicia. justicia.

Palabras clave: Escuela de Salamanca; derechos subjetivos; derechos humanos;

ABSTRACT: In this paper is intended to show the influence of te School of Salamanca in the constitution of the Human Rights. They received from the nominalists of Paris, where Vitoria and Soto studied, the idea of Subjective Rights, that some historians of Right consider the antecedents of the Human Rights, such as Blandine Barrett-Kriegel.

Key words: School of Salamanca, Subjective Rights, Human Rights, Justice. 


\section{INTRODUCCIÓN}

En estas páginas abordaré el tema de la justicia como fundamento del derecho. En efecto, tradicionalmente el derecho tenía como objetivo lo justo, esto es, la justicia. De ahí los tratados escolásticos De iustitia et iure, que abundaron en el siglo xvi. Era la perspectiva moral o ética del derecho. Así, una hermenéutica analógica tiene que buscar que el derecho sea justo, que la ley sea justa. Es la incorporación de la moral en el derecho, que tanta falta hace en la actualidad. Ya es algo que está avanzando en la filosofía actual del derecho, la reconexión del derecho con la moral, de modo que se busque, en definitiva, la justicia.

Una hermenéutica analógica nos ayudará a conectar esta idea de la justicia con los derechos humanos, pues en ellos es donde más resplandece esa búsqueda de la justicia, de lo moral; no en balde en algunas partes se los considera como derechos morales. Esa conexión del derecho con la moral se puede promover y fomentar, evitando un positivismo univocista y un relativismo equivocista. Todo ello en bien del ser humano, que es lo que en el fondo importa.

\section{Antecedentes de los derechos humanos en la Escuela de Salamanca}

Con justa razón se toma a la Escuela de Salamanca como la creadora de los derechos humanos. Eran los derechos naturales subjetivos. Tenían noción del derecho natural, tanto por la herencia grecorromana como por la medieval, tomista. Pero también, a pesar de lo que se ha dicho, que comienzan con Locke, tenían idea de los derechos subjetivos, ya que estos venían de Ockham, según lo asegura el célebre historiador del derecho Michel Villey. Por eso él los veía como traidores al tomismo, por ese injerto nominalista. De ahí que una discípula de Villey, Blandine Barret-Kriegel, dice que no fue en la Ilustración, sino en este tiempo y en esta escuela, donde surgen propiamente los derechos humanos ${ }^{1}$.

Y es que los principales fundadores de esa escuela, Francisco de Vitoria y Domingo de Soto, además del tomismo que aprendieron en su orden dominica, estudiaron en París con profesores nominalistas. Por eso recibieron, del tomismo, la idea del derecho natural, y del nominalismo, la de los derechos subjetivos, juntando en una síntesis ambos, como derechos naturales subjetivos, los cuales, según Barret-Kriegel, son lo mismo que nuestros derechos humanos actuales. Por ser naturales los tiene todo hombre y, por ser subjetivos, los tiene cada uno, según ese aprecio de lo individual que tuvieron los nominalistas.

Se han visto, sobre todo, en un seguidor de la Escuela de Salamanca que, sin haber estudiado en sus aulas, estuvo en contacto con esos maestros, a saber,

1. Barret-Kriegel, B.: Les droits de l'homme et le droit natural. Paris: PUF, 1989, p. 47 ss. Ver también Beuchoт, M.: "Derechos subjetivos, derechos naturales y derechos humanos». En VilLEGAS, A. et al.: Laberintos del liberalismo. México: UNAM - M. A. Porrúa, 1995, pp. 151-167. 
Bartolomé de las Casas ${ }^{2}$. Él puso en ejercicio esas ideas. Se conoce su correspondencia con Soto y se puede ver que usó a Vitoria en sus escritos de defensa de los indios, aunque discrepó de él en algunos puntos. Y lo que hizo en defensa de los indios lo hizo después en la de los negros, pues había pedido que se trajeran esclavos africanos a las Antillas porque los indios estaban siendo diezmados por el trabajo excesivo y los negros eran más resistentes; pero, recapacitando, se arrepintió de ello y también los defendió a ellos.

En México, es decir, en la Nueva España, la Escuela de Salamanca fue representada por Alonso de la Vera Cruz, un agustino, quien defendió los derechos de los indios en sus relecciones De dominio infidelium, donde sostiene que el dominio de los indios sobre sus tierras era legítimo, aunque fueran infieles (pues se suponía que el pecado mortal, como el de infidelidad, quitaba el derecho al dominio o posesión, pero él sostenía que no eran propiamente infieles, pues nunca habían oído del evangelio ni de la Iglesia Católica). Fray Alonso había estudiado precisamente en Salamanca, y citaba mucho a Soto en sus escritos.

Otro representante muy digno fue Tomás de Mercado, un dominico sevillano, que se formó en México pero fue a perfeccionarse en Salamanca, y en España publicó su libro Suma de tratos y contratos, donde habla de la justicia conmutativa, la que se da en los contratos y, al hablar de la esclavitud de los negros, que era una institución de derecho de gentes, se duele tanto de lo cruel que era, que uno ve que está yendo en contra de la esclavitud, en este caso de la de los negros.

Quizás el sistematizador de las ideas de esta escuela fue Francisco Suárez, jesuita, que fue muy leído tanto en España como incluso en los países protestantes ${ }^{3}$. Se ha estudiado la gran influencia que ejerció sobre los modernos, por ejemplo, en Spinoza y en Leibniz.

Un dato muy significativo es que estos pensadores asociaban los derechos naturales con la idea de justicia. Casi todos ellos escribieron un tratado De iustitia et iure, con lo que marcaban la dependencia del derecho con respecto a la moral, y es donde se ve ahora, en la filosofía del derecho, lo característico de los derechos humanos. Por eso pasaremos a considerar esta vinculación.

\section{DERECHO Y JUSTICIA}

Por supuesto que los de la Escuela de Salamanca dependieron de Aristóteles, a través de Santo Tomás. Y ya en el Estagirita encontramos esa idea de que los derechos humanos son una especie de derechos morales, esto es, derechos que

2. Beuchot, M.: «Derechos naturales y derechos humanos en Bartolomé de las Casas y la Escuela de Salamanca». En Villegas, A. et al:: Democracia y derechos humanos. México: UNAM - Miguel Ángel Porrúa, 1994, pp. 85-99.

3. Beuchot, M.: "La ley natural en Suárez». En: Cardoso, A., Martins, A. M. y Ribeiro dos Santos, L. (coords.): Francisco Suárez (1548-1617). Tradiçâo e modernidade. Lisboa: Eds. Colibri - Centro de Filosofia da Universidade de Lisboa, 1999, pp. 279-288. 
surgen cuando embonamos el derecho con la ética. Por cierto, es algo que se intenta volver a hacer en la actualidad.

Para Aristóteles, las relaciones humanas en la polis o sociedad se hallaban regidas o reguladas por la ley, lo cual tiene una gran proyección hacia la actualidad. Por eso, atendiendo al pensamiento del Estagirita y recuperándolo, es lo que mejor se puede esperar de un estudio de esa índole: que recupere a cabalidad el pensamiento aristotélico y que nos ilumine la ruta en nuestros días.

Esto es lo que toca a la filosofía del derecho. Ahora que tanto se cultiva esta disciplina filosófica, tiene que pedírsele ese esclarecimiento. Y lo primero que encontramos en este tipo de estudios, a la luz aristotélica, es que se nos recuerda que el objeto de la filosofía del derecho es lo que es justo ${ }^{4}$, y esto es algo que no siempre encontramos en los textos de filosofía del derecho al uso. De ahí la importancia de atender a ello.

Mas, para comprender a cabalidad la doctrina aristotélica, tenemos que establecer un contexto analógico para su estudio, esto es, utilizar como trasfondo la noción de analogía, tan importante en Aristóteles, quien la usa siempre en relación con los principios y las causas. De hecho, es principalmente el orden causal, o de manera especial se capta en el orden de las causas. En él tiene un papel preponderante y guía la causa final, que es la que ordena a todas las demás. Incluso, nuestro autor establece una lógica analógica para los conceptos que va a tratar, porque es el ámbito de la relación trascendental, tan fina y sutil, que se da entre esos elementos.

Aquí hay que hacer una conexión entre la justicia o lo justo y el derecho. Y, para ello, hay que recuperar el fundamento metafísico de las nociones que usamos. No olvidemos que la justicia era el objeto o la finalidad del derecho mismo (por eso los tratados De iustitia et iure, en cuyo título se indica la relación de esos conceptos). Pues bien, hay que recordar, también, que lo justo es el objeto de la justicia ${ }^{5}$. Y, en cuanto a la justicia, cabe centrarse sobre todo en la justicia legal, la justicia distributiva y la justicia correctiva. En estas nociones está presente la analogía de proporción, tanto de proporción aritmética como de proporción geométrica, las cuales determinan los distintos modos de la justicia ${ }^{6}$.

Así como la justicia tiene por fin lo justo, así lo justo tiene como fin el bien? Hay que referir el bien al ser, del cual es una propiedad trascendental, convertible con él. Además, hay que marcar de manera muy clara y firme la analogía del bien (que se relaciona con la analogía del ser). En el orden de los bienes, el de la felicidad es fundamental para el hombre ${ }^{8}$. Y, dentro de esos mismos bienes, lo justo ocupa un lugar preponderante; y también aquí se aplica la analogía de lo justo,

\footnotetext{
4. ARISTóteles, Ética a Nicómaco, 1129a1-5. (En adelante se citará como EN).

5. $E N, 1129$ a31 ss.

6. EN, 1130b11 ss.

7. $E N, 1130 \mathrm{~b} 5-11$.

8. EN, 1097 a30 ss.
} 
como uno de los modos del bien. Y esto se consigue con lo que en la tradición se llamó la recta razón, la cual es la que constituye a la verdadera racionalidad: no como una racionalidad fría y maquiavélica, sino como una racionalidad animada por el bien, por la intención de alcanzar el bien. (Es lo que en la filosofía actual se quiere lograr al distinguir entre razón instrumental y razón ética, según hace Habermas).

El momento central lo obtiene la crítica metafísica constitutiva de la noción de ley. Aquí la ley es vista como razón expresa de lo justo.? En efecto, la ley es instrumento y expresión de lo justo, causa instrumental para lograr el bien común de la sociedad.

Vemos entonces la actualización o perfección de la ley en su orden total y parcial, en dos despliegues sucesivos: el derecho en tanto que justo general y en tanto que justo particular. Pero siempre está lo justo como objetivo de la ley, tanto en lo universal como en lo individual. Y aquí reluce mucho el tratamiento de la prudencia legislativa, sin la cual no se puede alcanzar lo justo ni la justicia (ni, por ende, el bien común). Esta prudencia legislativa es la que conduce al ser-justo, o derecho, en sus dos modos principales ${ }^{10}$. A la prudencia, que es sumamente analógica, porque da el sentido de la proporción entre la ley y el caso, se añade otra virtud también muy analógica, que es la equidad, la aequitas de los latinos, que correspondía a la epeiqueia de los griegos, la cual ayudaba a aplicar la ley al caso con mucho tino, obteniendo lo más que se pudiera del bien ${ }^{11}$. Y es que después de saber qué es el derecho, se ha de pasar a ver cómo se ejerce.

Todo esto nos hace llegar a establecer lo justo como justo político, y lo justo político como justo natural y como justo legal ${ }^{12}$. De hecho, lo justo legal es lo justo político, pues se encamina al bien de la polis o ciudad. Y es que esta es la coronación del edificio ético, que desemboca en lo social o político. Es la consecución del bien común de la sociedad, en lo cual se cifra la mayor felicidad a nivel humano, anticipo de la felicidad sobrenatural que es la contemplación de Dios, autor del orden universal.

Algo muy importante es que encontramos criterios para distinguir lo justo natural de lo justo positivo ${ }^{13}$. Es esta una cuestión que se rehúye mucho en la actualidad, pero que hay que afrontar. En efecto, lo justo natural es fundamento (ontológico o metafísico) de lo justo positivo, y este último tiene que ser una expresión de aquel. En conclusión, encontramos que lo justo positivo o legal no añade nada a lo justo natural, sino que solamente lo realiza de una manera particular, dentro de la sociedad.

9. ARISTÓteles, Política, 1282b10-13.

10. EN, 1180b1.

11. $E N, 1137 \mathrm{a} 31-1137 \mathrm{~b} 35$.

12. $E N, 1134 \mathrm{a} 18-25$.

13. $E N, 1134 \mathrm{~b} 35-1135 \mathrm{a} 5$. 
Tenemos, así, que los conceptos clásicos de la filosofía del derecho tienen también aplicabilidad a nuestro tiempo actual. Ahora que estamos tan necesitados de la iluminación filosófica en el campo del derecho, nos viene muy bien atender a los conceptos jurídicos fundamentales y, sobre todo, a los de la filosofía del derecho, que toman mucho de la ética y la ontología. De esta manera tendremos una noción de derecho más ajustada al ser humano y, por lo mismo, más humana y humanista.

\section{APliCACión de la HeRMENÉUtica AL DERECHO}

Se pueden hacer aplicaciones muy interesantes de la hermenéutica al derecho, dentro de una ya larga tradición. Pero quisiera centrarme en una hermenéutica analógica, intermedia entre las hermenéuticas unívocas o rígidas, como las del cientificismo, y las hermenéuticas equívocas o blandas, como muchas de la posmodernidad $^{14}$. Esta hermenéutica analógica ya ha sido aplicada al derecho ${ }^{15}$. Es un tema de suma importancia, porque la práctica jurídica tiene mucho de interpretación. La hermenéutica jurídica ha llegado a colocarse como una de las asignaturas más típicas de la cultura jurídica.

Por eso el desarrollo de la hermenéutica analógica exige que sea llevada al ámbito del derecho, en el que la interpretación es muy necesaria. Y los esfuerzos que se han hecho para aplicar la hermenéutica analógica al derecho pretenden ayudar en la intrincada labor de la interpretación jurídica.

En primer lugar, la hermenéutica se coloca en las principales corrientes actuales del derecho, sobre todo las de filosofía jurídica o iusfilosofía; por ejemplo, se encuentra tanto en Bobbio como en Dworkin. De hecho, toca la parte epistemológica del derecho, pues la interpretación es un tipo de conocimiento.

Pero, sobre todo, es interesante encontrar en nuestro camino al gran hermeneuta Hans-Georg Gadamer, algunas de cuyas aportaciones podemos aplicarlas a la interpretación del derecho. Una de ellas nos hace colocar a la hermenéutica jurídica en el ámbito de la filosofía práctica, que es algo que el propio Gadamer hace con la hermenéutica, y, coherentemente, se puede hacer con la hermenéutica del derecho ${ }^{16}$.

Gadamer profesaba una hermenéutica ontológica, y de ella tenemos que dar el paso hacia una hermenéutica analógica, lo cual da el sentido de esta última, así como el de su oportunidad y validez. La hermenéutica ontológica, como la que se da en Gadamer, es un intento de colocar la interpretación como algo rico y a la vez

14. Beuchot, M.: Tratado de hermenéutica analógica. Hacia un nuevo modelo de la interpretación. México: UNAM-Ítaca, 2009 (4. ${ }^{\mathrm{a}}$ ed.), pp. 51 ss.

15. Barrera Vélez, J. C.: Pensar el derecho. Apuntes de hermenéutica jurídica. Cartagena, Colombia: Universidad de San Buenaventura, 2011, pp. 32 ss.

16. GadAmer,: Verdad y método. Fundamentos de una bermenéutica filosófica. Salamanca: Sígueme, 1977, pp. 383 ss. 
consistente, serio. No en balde Gadamer tomó en cuenta a Emilio Betti, que en su hermenéutica jurídica pretendía un rango muy alto de rigor ${ }^{17}$.

Lugar muy principal ocupa aquí la relación del comprender y el explicar, que la hermenéutica no separa sino que se esfuerza por acercar. El comprender tiene una estructura radicada en la tradición, que lleva ya pre-comprensiones muy considerables, a veces no concientizadas suficientemente. Es algo que en el derecho ha de ser muy relevante. Sobre todo porque implica conciencia de la historia, de la historia efectual, como la denomina Gadamer. El derecho es un hecho histórico, y tiene que contextuarse en su época.

Otra cosa es la condición lingüística del objeto de la interpretación. Lo que la hermenéutica estudia es lo que se pone de alguna manera en lenguaje. El propio Gadamer dice que el ser que podemos comprender es lenguaje ${ }^{18}$. Aquí se juntan la condición ontológica de la hermenéutica y su condición lingüística, incluso se podría decir que la una exige la otra.

También resalta el carácter dialógico de la hermenéutica. En el caso del derecho, al que parecería difícil aplicar esto, se da a través de la interacción entre los interlocutores para responder preguntas, para resolver problemas. Pero la dialógica llama a la analógica, a la razón analogante. Y aquí es donde se introduce la hermenéutica analógica, que aclara el sentido de la ley en su aplicación a los casos usando el instrumento de la analogía.

Sobre todo, me parece que la hermenéutica analógica es un intento de responder a las graves problemáticas (a veces se dice que crisis) de la posmodernidad, como ciertamente quiere serlo. Ahora que se han derrumbado los paradigmas científicos y filosóficos, y que todo parece ir hacia un relativismo total, tenemos el recurso a la analogía, que puede frenar ese relativismo exagerado en uno de sentido común y, además, brindarnos un paradigma suficiente para orientarnos.

Aquí surgen varios aspectos en relación con el derecho, como el epistemológico y el ético, pero se llega a la relación de la hermenéutica analógica con el derecho como la relación de la ley con el caso concreto. La ley es general, y el caso es particular. Para evitar el legalismo obtuso y la mera casuística, tenemos la ayuda de la analogía, que preserva las diferencias del caso, pero permite la aplicación de la ley en una universalidad matizada. Esto lo señala en comparación con Dworkin y Habermas. Hay que evitar el discrecionismo de los jueces, pero también el absolutismo legalista ${ }^{19}$. Hay que ir en la línea de la phrónesis.

Para eso se da el rejuego entre historia y dogmática del derecho, para centrar proporcionalmente cada uno de esos aspectos en la medida que se requiere. Esto tiene dos caras, pues una mira a la epistemología, cual es el tema de la verdad en la interpretación jurídica, pero otra mira a la ética, y es el tema de la justicia en la aplicación de la ley.

17. Ibid., pp. 396 ss.

18. Ibid., p. 567.

19. Dworkin, R.: Los derechos en serio. Barcelona: Planeta-Agostini, 1993, pp. 43 ss. 
Ya que el intérprete pertenece a una tradición jurídica, se plantea el problema de su apego a esa tradición y el de la creatividad que siempre se da dentro de una tradición dada. Esto ocurre también en la interpretación jurídica, y ha de balancearse hacia ambos lados. Así como las normas tienen prioridad sobre la interpretación del jurista, así también la tradición jurídica la tiene sobre su «libertad», la cual corre el peligro de apartar de la justicia.

Hay un concepto muy importante e interesante que se usa en la cultura jurídica, y es el de mediación. La mediación implica cierta dialéctica, es verdad; hay una dialéctica en esta interacción jurídica. En eso consiste el carácter científico del derecho, o, si se prefiere, del carácter hermenéutico de la ciencia jurídica. Es la dialéctica de lo general y lo particular en el derecho, en la cual reside la posibilidad de alcanzar la justicia, el cumplimiento del bien.

Para resolver esa dialéctica, esa oposición, disponemos de dos virtudes aristotélicas que son sumamente analógicas, a saber, la phrónesis y la epeikeya. La phrónesis o prudencia nos hace encontrar las analogías del caso, y es por lo que en la historia del derecho se ha hablado de jurisprudencia. El jurisprudente es el que encuentra la analogía de un caso con otros. La epeikeya, que los latinos tradujeron como equitas, esto es, equidad, es la virtud del juez, que tiene tacto para aplicar la ley al caso concreto sin herir a nadie, sino, al contrario, sacando el mayor bien para todos. Ambas cosas son muy analógicas, por eso es deseable una hermenéutica analógica para el derecho.

\section{Hermenéutica analógica para el Derecho}

He dicho que la hermenéutica siempre ha habitado en el seno del derecho. Pero en el derecho mismo se ha dado la tentación de aspirar con demasiada presunción a una hermenéutica rígida, unívoca, la ansiedad de la univocidad, así como la tentación de derrotarse y caer en una hermenéutica equívoca, la depresión de la equivocidad. Y en todo caso es mejor buscar un punto intermedio y mediador, el de una hermenéutica analógica, que lucha contra el arrastre de la falta de sentido, y se esfuerza por lo que es alcanzable de rigor y objetividad en la comprensión del fenómeno jurídico ${ }^{20}$.

En el campo del derecho es bien sabido que pocas veces se alcanza una interpretación unívoca, un sentido plenamente literal, una comprensión clara y distinta del texto jurídico. Siempre queda lugar para la ambigüedad, para la vaguedad, para las lagunas, etc. Pero eso no significa que se vaya la interpretación del derecho al equivocismo, pues eso es derrotarse y renunciar a lo que la hermenéutica jurídica tiene por finalidad, que es lograr lo más posible que sea la claridad y la comprensión de los textos jurídicos. Eso es lo humanamente alcanzable, y por eso allí es

20. Beuchot, M.: Filosofía del derecho y hermenéutica analógica. San Luis Potosí, S.L.P.: Universidad Autónoma de San Luis Potosí, 2010 (3. ${ }^{\text {a }}$ ed.), pp. 107 ss. 
donde encuentra aplicación una hermenéutica analógica, ya que alcanza el mayor grado de claridad que es conseguible. Y eso nos basta para alcanzar la justicia, que es, en definitiva, la meta de toda la investigación jurídica.

La hermenéutica y el derecho ya han tenido varios contactos, en toda una historia que hay de la hermenéutica jurídica. La interpretación de los textos jurídicos tiene ya una larga historia. Basta aludir a los romanistas y a los canonistas, que llenan la Edad Media. Pero la jurisprudencia siempre ha estado muy presente, y ella recorre toda la historia del derecho. En efecto, una de las prácticas jurídicas fundamentales es la de interpretar los documentos e instrumentos del derecho. Siempre quedan ambigüedades, pero el jurisprudente las resuelve acudiendo al sentido que cobran en el corpus del derecho y, además, por su conocimiento del espíritu de la letra, esto es, de la intencionalidad del legislador, así como de la finalidad del derecho que es conseguir la equidad y la justicia, el bien de la sociedad y sus individuos.

Pero hay que evitar la desesperada ambición de univocidad en la interpretación del derecho. Prácticamente es inalcanzable una hermenéutica jurídica unívoca o univocista. Por supuesto que una hermenéutica jurídica equívoca o equivocista es inservible y hasta contraria a los fines del derecho. Por eso es tan importante colocarse en esa postura mediadora que es la de una hermenéutica analógica, la cual aspira tendencialmente a la objetividad; en todo caso, se exige rigor y precisión, pero sabe que en ello hay limitaciones; mas no por eso se deja vencer y caer en la pura ambigüedad, que propiciaría la injusticia. Una hermenéutica así, analógica, puede darnos una comprensión del derecho lo más clara que sea humanamente alcanzable, lo cual sería ya bastante, y, sobre todo, suficiente para lograr ese ideal de justicia en la sociedad ${ }^{21}$.

Estamos en un momento en el que precisamos recuperar el ámbito de la moral, de la ética, para el derecho. Esto es lo que se ha querido realizar con el iusnaturalismo. Ahora, en lugar de hablar de derechos naturales hablamos de derechos humanos. Pero tenemos que buscarles su fundamentación. Ella nunca está de más, si mantenemos una exigencia filosófica, o una idea de la filosofía exigente, que no se contente con soluciones pragmáticas a veces muy apresuradas, sino que se obligue a calar hondo en el sustrato ontológico del ser humano, que es el del derecho mismo.

Cada vez más se exige el estudio del ser humano para plantear el derecho. Analizar su naturaleza para ver qué derecho le convenía. Esto era visto como falacia naturalista, porque es pasar de lo descriptivo a lo valorativo, lo cual se supone que es un paso en falso; pero ahora la misma falacia naturalista está desacreditada, pues -como lo hace ver Hilary Putnam- incurre ella en petición de principio y se

21. Beuchот, M.: Hermenéutica analógica y derecho. Buenos Aires: Rubinzal-Culzoni Eds., 2008, pp. 63 ss. 
comete reducción al absurdo ${ }^{22}$. En efecto, acusar de falacia naturalista es cometer falacia naturalista (pues supone pasar de la mera descripción a la valoración) y, por ello, resulta que, para ser buen iuspositivista, hay que ser buen iusnaturalista.

El hecho es que solamente basándonos en la antropología filosófica y, por lo tanto, en la ontología o metafísica, podemos garantizar un derecho humano o conforme con el ser del hombre y que le sea conveniente. De otra manera, estaremos construyendo a ciegas, solamente un derecho puramente normativista y, a veces, totalmente injusto e inhumano.

\section{El CAMino de los derechos humanos}

Sobre todo, se puede aplicar esto al caso de los derechos humanos. Ellos presentan numerosos casos difíciles, por la colisión que a veces se da entre dos o más de ellos. O también por las ambigüedades que pueden quedar. O también por las diversas interpretaciones que de ellos hacen diferentes culturas o etnias. Siempre se ha de dar cierta amplitud en la diversidad de interpretaciones, pero nunca cuando eso vaya en contra de los derechos humanos mismos, de lo que podemos llamar su esencia o contenido.

Martin Kriele entiende los derechos humanos como un logro de la Ilustración, en el camino de la libertad ${ }^{23}$. Sostiene que solo pueden darse en la democracia, y esta solo puede garantizarse cuando hay división de poderes, pues si el poder ejecutivo, el legislativo y el judicial están en manos de un mismo individuo o grupo, eso es la tiranía, el despotismo.

Además, los derechos humanos se basan en la dignidad del hombre ${ }^{24}$. Esto se encuentra expresado en una de las formulaciones del imperativo categórico de Kant, en el sentido de que nunca debemos usar a los demás hombres como medios, sino siempre como fines. Eso es darles un estatuto de valiosos moralmente, y es la manera de resguardar su dignidad humana.

Y esta fundamentación de los derechos humanos en la dignidad humana dentro de una democracia es ganar en libertad. La dignidad está vinculada con la libertad humana, pues solo respetando la dignidad del hombre se le respeta el alcance de su libertad. Y la raíz de la dignidad humana es la obligatoriedad del imperativo categórico kantiano ${ }^{25}$. Es lo que le da validez, y es un principio moral; donde volvemos a ver la conexión de la moral con el derecho, conexión que recientemente se ha querido recuperar; también se quiere volver a conectar la moral con la economía, la política, etc.

22. Putnam, H.: El desplome de la dicotomía hecho-valor y otros ensayos. Barcelona: Paidós, 2004, pp. 166-167.

23. Kriele, M.: Liberación e Ilustración. Defensa de los derechos humanos. Barcelona: Herder, 1982, p. 36

24. Ibid., p. 49.

25. Ibid., p. 53. 
La relación de los derechos humanos con la dignidad humana nos enlaza con la misma naturaleza humana. Porque, ¿de dónde, si no, surge la dignidad humana si no es de la naturaleza humana? Es como cuando los derechos humanos se basan en las necesidades primarias del hombre. Esas necesidades vuelven a remitirnos a la naturaleza humana, que es a la que corresponden, de la que brotan. Ya se la llame naturaleza humana, o condición humana, es el asiento y base de la dignidad humana.

Como su nombre lo dice, los derechos humanos tratan de rescatar un derecho que sea humano, esto es, conforme con la naturaleza del hombre y conveniente a ella. Por eso tenemos que estudiar al hombre mismo, para ver su dignidad, la naturaleza humana en la que se funda y las necesidades básicas que engendra. Eso nos ayudará a tener un derecho verdaderamente humano. Y eso podremos hacerlo mediante una hermenéutica del ser humano, que alimente la antropología filosófica y llegue hasta la ontología, que es en la que finalmente descansa nuestra comprensión del hombre mismo, porque en ella se asienta, en verdad, todo nuestro conocimiento de la realidad.

De esta manera, la hermenéutica analógica será de gran ayuda para la interpretación adecuada de los derechos humanos, porque aspira a recuperar la noción de naturaleza humana, como algo que trasciende la historia y las culturas; sobre todo será útil cuando tales derechos se encuentren en un ámbito multicultural, ya que a veces reciben diferentes sentidos en las distintas culturas o etnias que los realizan ${ }^{26}$. Y se puede, como lo exige la analogía, tratar de favorecer la diferencia, pero siempre dentro de un límite en el que no se lesione la esencia o naturaleza de los derechos humanos mismos. Hay un límite de la interpretación, más allá del cual el intérprete corre el riesgo de estar cambiando la esencia de las cosas, en este caso, la de los derechos humanos, que no pueden ser interpretados tan laxamente que con ello se destruya su naturaleza y los subvierta. Y por eso la hermenéutica necesita los límites que le puede aportar la antropología filosófica y la ontología o metafísica.

\section{CONClusión}

Según hemos podido apreciar, la historia de los derechos humanos no comienza con la Ilustración (Locke) ni con la Revolución Francesa, sino con la Escuela de Salamanca. Los ilustrados concedían derechos humanos al ciudadano (le citoyen), es decir, al francés, al europeo, mientras que los teóricos de Salamanca, como Las Casas, los concedían a todos, incluyendo a los indios y a los negros, a los que no tomaban en cuenta los otros. Por eso puede decirse que era una teoría más abarcadora, experimentada en el caso real y urgente de defender a aquellos seres humanos. Esto se debe a que vinculaban el derecho con la justicia, es decir,

26. Beuchot, M.: Interculturalidad y derechos humanos. México: Siglo xxi, 2005, pp. 37 ss. 
con la moral, como lo mostraban sus numerosos tratados De iustitia et iure. Es algo que apenas en tiempos muy recientes se está recuperando, tras muchos años de positivismo.

Además, en estos andares hemos visto cómo la hermenéutica puede beneficiar al derecho, porque este casi siempre requiere de interpretación. Mas dicha interpretación tiene que encontrar un término medio, de modo que evite la univocidad pretenciosa y la equivocidad desgastada. Una hermenéutica analógica es la que se muestra como benéfica para él. Ella se colocará entre los dos extremos, sin pretender la exactitud unívoca ni derrumbarse en la ambigüedad equívoca. Sabrá conservar su lugar intermedio y mediador. Servirá especialmente en el caso de multiculturalismo, para una visión intercultural de tan importantes derechos.

Tal utilización de la hermenéutica analógica con el fin de aplicarla al derecho, sobre todo a los derechos humanos, nos ayudará a recuperar la conexión del derecho con la moral, y además con la ontología. Esto a través de una antropología filosófica o filosofía del hombre (caída ya toda sospecha o acusación de falacia naturalista, que se muestra ya como superada y abandonada). Porque si no tenemos un conocimiento del hombre, mal podríamos asignarle un derecho que le corresponda y que le convenga y que le sea proporcional o proporcionado. Inevitablemente, la conexión del derecho con la moral nos conduce a la moral o ética, y esta a la antropología filosófica en la que se sustenta, y esta a la ontología en la que se funda. 